



National Bureau of Standards

Library, E.01 Admin. Bldg.
DCT 61981
191105
QC
100
4.5753

\section{SCATTERING-MATRIX DESCRIPTION AND NEAR-FIELD MEASUREMENTS OF ELECTROACOUSTIC TRANSDUCERS}

\section{$Q C$ 100 15753 18.651 \\ 1974 \\ c.2} PARTMENT OF OMMERCE

National Bureau of Standards 


\section{NBS TECHNICAL PUBLICATIONS}

\section{PERIODICALS}

JOURNAL OF RESEARCH reports National Burcau of Standards research and development in physics, mathematics, and chemistry. Comprehensive scientific papers give completc details of the work, including laboratory data, experimental procedures, and thcoretical and mathematical analyses. Illustrated with photographs, drawings, and charts. Includes listings of other NBS papers as issued.

Published in two sections, available separately:

\section{- Physics and Chemistry (Section A)}

Papers of interest primarily to scientists working in these fields. This section covers a broad range of physical and chcmical research, with major emphasis on standards of physical measurement, fundamental constants, and properties of matter. Issued six times a year. Annual subscription: Domestic, $\$ 17.00$; Foreign, \$21.25.

\section{- Mathematical Sciences (Section B)}

Studies and compilations designed mainly for the mathematician and theoretical physicist. Topics in mathematical statistics, thcory of experiment design, numerical analysis, theoretical physics and chemistry, logical design and programming of computers and computer systems. Short numerical tables. Issued quarterly. Annual subscription: Domestic, $\$ 9.00$; Foreign, $\$ 11.25$

\section{DIMENSIONS, NBS}

The best single source of information concerning the Bureau's measurement, research, developmental, cooperative, and publication activities, this monthly publication is designed for the layman and also for the industry-oriented individual whose daily work involves intimate contact with science and technology - for engineers, chemists, physicists, research managers, product-development managers, and company executives. Annual subscription: Domestic, $\$ 6.50 ;$ Foreign, $\$ 8.25$.

\section{NONPERIODICALS}

Applied Mathematics Series. Mathematical tables, manuals, and studies.

Building Science Series. Research results, test methods, and performance criteria of building matcrials, components, systems, and structures.

Handbooks. Recommended codes of engineering and industrial practice (including safety codes) developed in cooperation with interested industries, professional organizations, and regulatory bodies.

Special Publications. Proceedings of NBS conferences, bibliographies, annual reports, wall charts, pamphlets, etc.

Monographs. Major contributions to the technical literature on various subjects related to the Bureau's scientific and technical activities.

National Standard Reference Data Series. NSRDS provides quantitative data on the physical and chemical properties of materials, compiled from the world's literature and critically evaluated.

Product Standards. Provide requirements for sizes, types, quality, and methods for testing various industrial products. These standards are developed cooperatively with interested Government and industry groups and provide the basis for common understanding of product characteristics for both buyers and sellers. Their use is voluntary.

Technical Notes. This series consists of communications and reports (covering both other-agency and NBS-sponsored work) of limited or transitory interest.

Federal Information Processing Standards Publications. This series is the official publication within the Fcderal Government for information on standards adopted and promulgated under the Public Law 89-306, and Bureau of the Budget Circular A-86 entitled, Standardization of Data Elements and Codes in Data Systems.

Consumer Information Series. Practical information, based on NBS research and experience, covering areas of interest to the consumer. Easily understandable language and illustrations provide useful background knowledge for shopping in today's technological marketplace.

\section{BIBLIOGRAPHIC SUBSCRIPTION SERVICES}

The following current-awareness and literature-survey bibliographies are issued periodically by the Bureau:

Cryogenic Data Center Current Awareness Service (Publications and Reports of Interest in Cryogenics). A literature survey issued weekly. Annual subscription: Domestic, $\$ 20.00$; foreign, $\$ 25.00$.

Liquefied Natural Gas. A literature survey issued quarterly. Annual subscription: $\$ 20.00$.

Superconducting Devices and Materials. A literature survey issued quarterly. Annual subscription: $\$ 20.00$. Send subscription orders and remittances for the preceding bibliographic services to the U.S. Department of Commerce, National Technical Information Service, Springfield, Va. 22151.

Electromagnetic Metrology Current Awareness Service (Abstracts of Selected Articles on Measurement Techniques and Standards of Electromagnetic Quantities from D-C to Millimeter-Wave Frequencies). Issued monthly. Annual subscription: $\$ 100.00$ (Special rates for multi-subscriptions). Send subscription order and remittance to the Electromagnetic Metrology Information Center, Electromagnetics Division, National Bureau of Standards, Boulder, Colo. 80302.

Order NBS publications (except Bibliographic Subscription Services) from: Superintendent of Documents, Government Printing Office, Washington, D.C. 20402. 


\section{SCATTERING-MATRIX DESCRIPTION AND NEAR-FIELD MEASUREMENTS OF ELECTROACOUSTIC TRANSDUCERS}

National Burearu of Stanciards MAY $6 \quad 1974$

D.M. Kerns

Electromagnetics Division

Institute for Basic Standards

National Bureau of Standards

Boulder, Colorado 80302

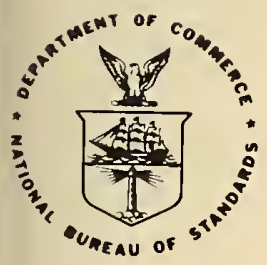

U.S. DEPARTMENT OF COMMERCE, Frederick B. Dent, Secretary NATINAL BUREAU OF STANDARDS. RIChard W. Roberts, Director Issued March 1974 


\section{National Bureau of Standards Technical Note 651}

Vat. Bur. Stand. (I.S.), Teerh, Note 651. 40 pages (March 1974)

(OIDE: NBTNAE

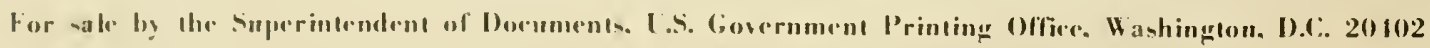

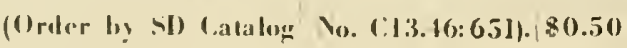


CONTENTS

$\underline{\text { Page }}$

ABSTRACT - . $\ldots \ldots \ldots \ldots \ldots$

1. INTRODUCTION-....... 2

2. SCATTERING-MATRIX DESCRIPTION OF TRANSDUCERS--.-.- 8

3. SCATTERING-MATRIX ANALYSIS OF COUPLED TRANSDUCERS - - 16

4. TRANSVERSE SCANNING AND DECONVOLUTION -......... 23

5. RECEIVED SIGNAL AS A FUNCTION OF DISTANCE AND THE

EXTRAPOLATION TECHNIQUE $\ldots \ldots \ldots$

APPENDIX: EXPANSION OF $b_{0}^{\prime}(\mathrm{d}) / \mathrm{a}_{0} \ldots \ldots$

REFERENCES - . . . . . . . 37

FIGURES

Figure 1. Transmission system -- schematic-_........ 4

Figure 2. Far electric-field amplitude determined from near-field data for JPL microwave horn antenna 26

Figure 3. Character of data and extrapolation-....... 28

Figure 4. (a) Domains of $Q$ and $Q^{\prime a}$; (b) composition of the vector $\rho$ 

David M. Kerns

\section{ABSTRACT}

Recently developed and successfully applied analytical techniques for the measurement of microwave antennas at reduced distances are "translated" into corresponding techniques for the measurement of electroacoustic transducers in fluids. The basic theory is formulated in scattering-matrix form and emphasizes the use of plane-wave spectra for the representation of sound fields. This theory, in contrast to those based on asymptotic description of transducer characteristics, is suitable for the formulation and solution of problems involving interactions at arbitrary distances. Two new techniques (in particular) are described: One, utilizing deconvolution of planar scanning data, taken with a known transducer at distances $d$ which may be much less than the Rayleigh distance $d_{R}\left(\equiv D^{2} / 2 \lambda\right)$, provides a means of obtaining complete effective directivity functions, corrected for the effects of the measuring transducer. App $\overline{1 i c a b i l i t y ~ o f ~ a ~}$ (two-dimensional, spatial) sampling theorem and the "fast Fourier transform" algorithm, which greatly facilitate the necessary computations, is shown. The second technique provides a means of extrapolating received signal as a function of distance (observed with $d \sim d_{R}$ ) to obtain on-axis values of effective directivity. Other possible applications are indicated. These techniques rigorously utilize observed output of non-ideal (but linear) measuring transducers.

Key words: Electroacoustic transducer measurement techniques; near-field measurement techniques; scattering matrix description of electroacoustic transducers. 


\section{INTRODUCTION}

Recently, a considerable amount of experimental, computational, and theoretical work in the development of new techniques for measurement of microwave antennas at reduced distances has been successfully completed [1-6]* at the National Bureau of Standards (and the work is continuing). It seems more than likely that analogous techniques may be found useful in the measurement of electroacoustic transducers. The main purpose of this paper is to "translate" some of the new electromagnetic techniques into the corresponding acoustic techniques. This entails reformulation of some of the scattering-matrix formulation that has been used in the electromagnetic problems, and it is suggested that this formulation may be found useful and fruitful in acoustics--as it has been in electromagnetics. In this new formulation, "antenna" is replaced by "transducer" and free "space" is replaced by homogeneous, nonviscous, stationary "fluid." All devices, both in the original theory and in this application, must exhibit linear behavior (at least from an external point of view), and sma11-amplitude (1inearized) equations of sound propagation are assumed. The resulting theoretical structure is otherwise essentially free of restrictive assumptions and built-in approximations. (A similar statement applies in the electromagnetic case, with the helpful feature there that Maxwell's equations are not inherently non-1inear.)

For fluids, the governing differential equations (eqs 2-2) are appreciably simpler than Maxwell's equations and consequently the scattering matrix formulation in the acoustics case is appreciably simpler than in the electromagnetics case. On the other hand, the derivation of

*Figures in brackets indicate the 1 iterature references at the end of this paper. 
supporting theorems of appreciable generality, such as those for reciprocity and adjoint reciprocity [13], is of course more complicated in the electroacoustics case than in the purely electromagnetic case. However, the reciprocity relations can easily be stated and applied in the plane-wave scattering-matrix formalism, and those needed are stated and applied in this paper.

The new techniques seem 1 ikely to be of most interest for transducers of moderate to high directivity. In discussing transducer separation distances required for measurement purposes, we assume (1) $\mathrm{kD} \gg 1$, where $\mathrm{k}=2 \pi / \lambda$ is the magnitude of the pertinent propagation vector and $D$ is a representative transverse dimension of the transducer aperture, and (2) applicability of the concept of the Rayleigh distance, $d_{R}$, defined as $D^{2} /(2 \lambda)$. This type of case appears to present the most severe distance requirements. We next give an introductory discussion of the two measurement techniques mentioned in the abstract, both of which enable accurate measurements to be made at reduced distances.

The first of these, the planar scan-deconvolution technique (including application of a spatial sampling theorem) was formulated for antennas by Kerns [1]. Experimental results have been given by Baird et a1. [3] and by Joy and Paris [7].

Thus, in figure 1 , we suppose that the radiating characteristic (i.e., the spectrum $S_{10}(\underline{\mathrm{K}}) *$ ) of the transducer on the left is to be determined with a known measuring

*Later in this paper, it is shown how the radiating and receiving characteristics of transducers may respectively be described in terms of plane-wave spectral functions such as $\mathrm{S}_{10}(\underline{K})$ and $\mathrm{S}_{01}(\underline{\mathrm{K}})$, where $\underline{K}$ is a variable specifying the direction associated with each spectral component. 


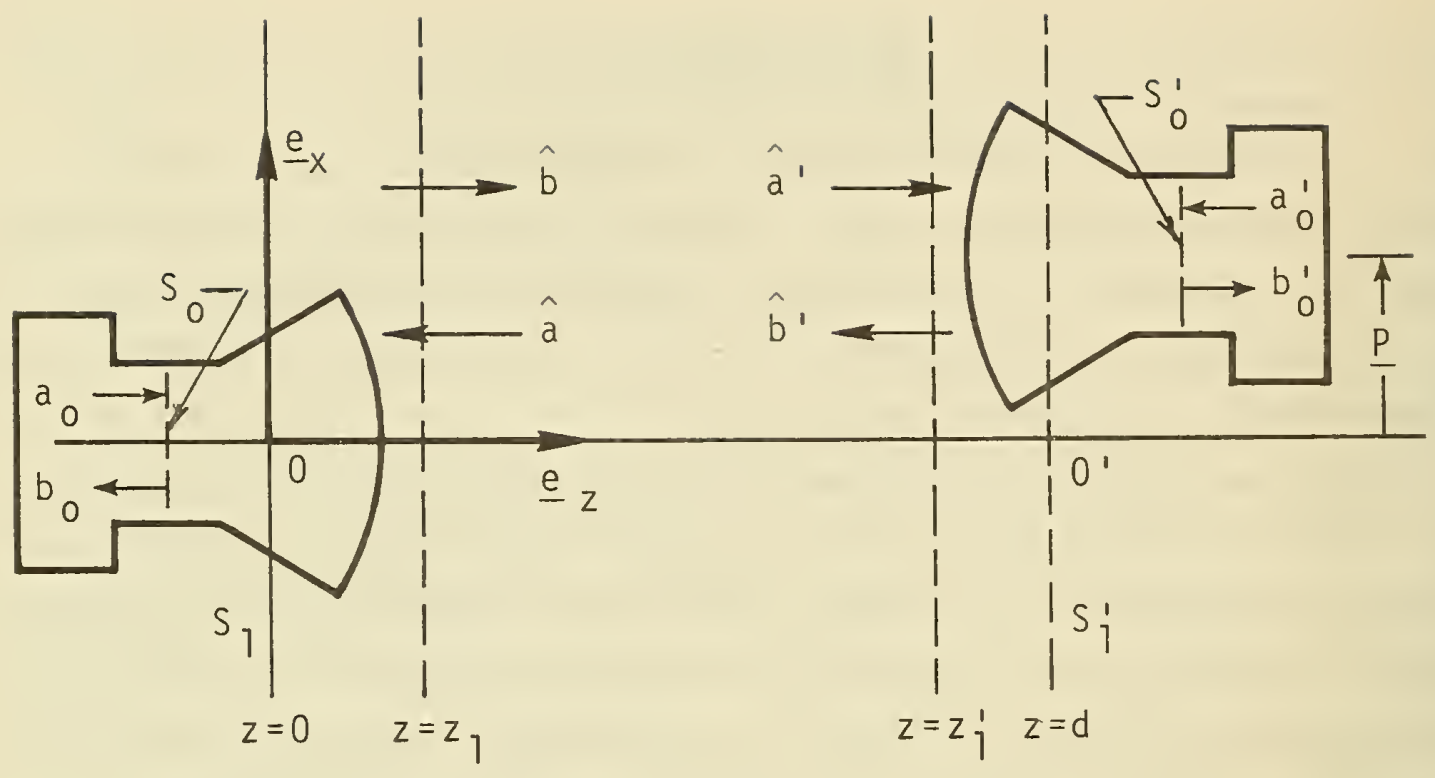

Figure 1. Transmission system -- schematic.

transducer (i.e. one with $\mathrm{S}_{01}(\underline{K})$ known) on the right, which is used to scan the field of the transmitter in a transverse plane $(z=$ const. $)$ a short distance $\left(d<d_{R}\right)$ away from the transmitter. If, as is required in this technique, multiple reflections between the transducers are negligible, the radiated spectrum is given by the Fourier transform of the acoustic pressure in the measurement plane. What we may call an ideal probe would measure this pressure directly, even in the near field; an actual probe, however, yields a response given by a convolution integral involving both the structure of the pressure distribution and the characteristics of the probe itself. In $\S 4$ we give a rigorous analytical technique for obtaining the true spectrum, $S_{10}(\underline{K})$, of the unknown transducer, corrected for the effects of an arbitrary, but known receiving transducer.

A knowledge of $\mathrm{S}_{10}(\underline{\mathrm{K}})$ enables one to find the pressure field that would be produced by the transmitting transducer in the absence of the receiving transducer. The pressure 
distribution in a transverse plane $z=z_{2}$, say, at any distance beyond (and within limits, inside) the measurement plane is given by a Fourier integral depending on $\mathrm{S}_{10}(\underline{K})$ and on $z_{2}$ (eq 2-9b); in the limit of large distance, the far-field (hence far-field pattern) is given almost directly in terms of $\mathrm{S}_{10}(\underline{\mathrm{K}})$ (eq 2-12).

The second analytical technique to be described here is identifiable as an extrapolation technique. This technique was introduced for antennas by Wacker and Bowman, has been described very briefly by Newell and Kerns [4], and, more fully, in an experimentally oriented paper, by Newell et al. [5]. The theory and numerical techniques were developed by Wacker [6]. In the extrapolation technique, one observes the received signal as a function of separation distance $d$ (fig. 1), and it is not necessary to assume that multiple reflections are negligible. For a given axial alignment of the transducers involved, the technique yields only on-axis data and requires only on-axis characterization of the receiving transducer. It should permit measurements to be made with $d \sim d_{R}$ with accuracy equal to that attainable by conventional means only with $\mathrm{d}>\mathrm{d}_{\mathrm{R}}$.

In the above discussion of the near-field scanning and the extrapolation techniques, we have assumed for definiteness that an unknown transmitting transducer was to be measured with a known receiving one. However (as is necessarily the case), what is basically measured is the product of two factors, one $\left(\mathrm{S}_{10}\right)$ characteristic of the transmitting transducer and one $\left(\mathrm{S}_{01}\right)$ characteristic of the receiving transducer. This means that data (obtained at reduced distances) can be used in additional ways (which are familiar in transducer or antenna measurements, or both): 
The receiving characteristic may be determined if the transmitting characteristic is known; on-axis $(\underline{K}=0)$ characteristics of two identical unknown transducers (subject to a reciprocity or equivalent relation) can be determined; three dissimilar unknown transducers can be calibrated, provided at least one satisfies a reciprocity relation.

The transverse scanning technique offers still another measurement possibility, which may well be new: Characteristics of two identical transducers obeying reciprocity and possessing symmetry with respect to an axial plane (e.g., y $=0$ ) may be determined for all $\underline{K}$ (corresponding to real directions with $z>0$ ) from one complete transverse scan. This last possibility is to some extent peculiar to the acoustics case; the corresponding achievement using two identical antennas requires higher symmetry. Equations for the application of the planar scan-deconvolution technique to the two-identical transducer measurement problem are readily derivable with the aid of the formulation given in this paper. The corresponding antenna measurement problem is discussed in [2].

The problem of determining far-field characteristics from near-field data, particularly for large underwater sound transducers, has received a good deal of attention in the literature. Apparently two main approaches have evolved: (1) Far-field simulation by large phased arrays, which produce (or respond to) a locally approximate planewave in their near-field regions [8,9] -- Measurements on devices placed in the substantially uniform portion of such near fields are essentially direct. (2) Application of Kirchhoff diffraction theory, using the free-space Green's function $[10,11]$-- This requires both pressure and 
normal velocity data over the chosen measurement surface. Although accuracies of $\pm 1 \mathrm{~dB}$ have been reported, higher accuracy may be limited by the difficulty of obtaining or approximating normal velocity data, as well as by inaccuracy in pressure data yielded by non-ideal measuring transducers in the near-field.

It should be observed that the use of a Green's function satisfying homogeneous Dirichlet boundary conditions on the chosen measurement surface (and vanishing properly at infinity) would eliminate the need for normal velocity data and thus solve this particular part of the measurement problem. For sufficiently simple surfaces (e.g., cylindrical and spherical) such Green's functions may be found in the form of modal expansions; in the particular case of a plane surface, a suitable Green's function may be constructed (in closed form) as an antisymmetric combination of free-space Green's functions .

Apparently the plane-wave scattering-matrix approach has not previously been formulated for acoustics applications.* The power of this approach is perhaps most evident in the ease of formulation and the potential advantages of the planar scanning-deconvolution technique (above and $\S 4$ ). This particular technique seems likely to be most applicable when relatively complete pattern information is needed for transducers of moderate to high directivity. The potential advantages include: (1) The ability to make measurements with separation distances much less than the Rayleigh distance (or at any convenient distance). (2) The ability to use, and correct for the effects of, a single non-ideal (but well characterized) measuring transducer. (3) The applicability of a (two-dimensional, spatial) sampling theorem and the

*This paper reproduces the substance of an unpublished NBS report [24]. A talk on the subject was given by the author at the 84 th meeting of the Acoustical Society of America, Miami Beach, Florida, 28 November - 1 December, 1972. 
highly efficient "fast Fourier transform" algorithm in the required computations.

\section{SCATTERING-MATRIX DESCRIPTION OF TRANSDUCERS}

Let us consider first the system shown schematically on the left in figure 1 . The transducer we wish to consider relates phenomena occurring on the reference surfaces $S_{0}$ and $z=z_{1}$. Connection to a (shielded) source or load by means of electrical waveguide (such as coaxial transmission 1 ine) is perhaps suggested by the figure, but other means of connection (e.g., by wire) are not excluded. The connection might indeed be acoustic waveguide, but this case will not be considered explicitly. Whatever the terminal variables are, we wish to consider them expressed at least formally in terms of traveling-wave components. In the electrical case, phasor wave amplitudes $a_{0}$ and $b_{0}$ for incident and emergent waves at $\mathrm{S}_{0}$ may be defined in terms of voltage $\mathrm{V}_{0}$ and current $I_{0}$ by the equations $V_{0}=a_{0}+b_{0}$ and $I_{0}=\left(a_{0}-b_{0}\right) n_{0}$, where $n_{0}$ is characteristic admittance. (We remark that $V_{0}$ and $I_{0}$ could be used directly, but the variables chosen are better suited to the application of the scattering matrix concept.) Assuming peak-value normalization, the net time-average power input to the transducer at $S_{0}$ is given by

$$
\mathrm{P}_{0}=\frac{1}{2} n_{0}\left(\left|\mathrm{a}_{0}\right|^{2}-\left|\mathrm{b}_{0}\right|^{2}\right)
$$

where the vertical bars denote absolute values.

Propagation in the fluid medium surrounding the transducer is governed by the equations

$$
\begin{aligned}
\rho_{\mathrm{o}} \mathrm{c}^{2} \nabla \cdot \underline{\mathrm{u}} & =i \omega \mathrm{p}, \\
\nabla \mathrm{p} & =i \omega \rho_{\mathrm{o}} \underline{\mathrm{u}},
\end{aligned}
$$


where $\rho_{0}$ is the mean fluid density, $c$ is the characteristic speed of propagation, $\underline{u}$ is the acoustic particle velocity, $p$ is the acoustic pressure, and $\exp (-i \omega t)$ time dependence has been as sumed.

We employ a coordinate system oxyz with unit vectors $\underline{e}_{x}, \underline{e}_{-y}$, and $\underline{e}_{z}$, and let $\underline{k}$ denote the propagation vector for plane waves in the fluid surrounding the transducer. $k$ will be regarded as a function of its transverse components $k_{x}$, $k_{y}$ (throughout this discussion "transverse" means perpendicular to the $z$-direction); the $z$-component of $k$ is then

$$
\mathrm{k}_{z}= \pm \gamma
$$

where $\gamma^{2}=\left(k^{2}-k_{x}^{2}-k_{y}^{2}\right)$ and $k^{2}=\omega^{2} / c^{2}$. The transverse part of $\underline{k}$ is denoted by $\underline{K}$, so that $\underline{K}=k_{x-x} \underline{e}_{x}+\dot{k}_{y} \underline{e}_{y}$, and

$$
\gamma=\left(k^{2}-K^{2}\right)^{\frac{1}{2}},
$$

where $\gamma$ is taken positive for $\mathrm{K}^{2}<\mathrm{k}^{2}$ and positive imaginary for $\mathrm{K}^{2}>\mathrm{k}^{2}$. We note that a plane wave solution $\exp (\mathbf{i k} \cdot \underline{r})$ of eqs (2-2) for $p$ may be written in the form

$$
e^{i \gamma z} e^{i K} \cdot \underline{R}
$$

where $\underline{r}=\underline{R}+z \underline{e}_{z}$, and we also note that both propagated (homogeneous) and evanescent (inhomogeneous) plane waves are represented.

For the pressure $\mathrm{p}$ and for the $\mathrm{z}$-component of the particle velocity $u_{z}$, we introduce the plane-wave (Fourier integra1) representations

$$
\begin{aligned}
& p(\underline{r})=\frac{1}{2 \pi} \int\left[b(\underline{K}) e^{i \gamma z}+a(\underline{K}) e^{-i \gamma z}\right] e^{i \underline{K} \cdot \underline{R}} d \underline{K}, \\
& u_{z}(\underline{r})=\frac{1}{2 \pi} \int \eta(K)\left[b(\underline{K}) e^{i \gamma z}-a(\underline{K}) e^{-i \gamma z}\right] e^{i \underline{K} \cdot \underline{R}} d \underline{K},
\end{aligned}
$$


where $n(K) \equiv \gamma /\left(\omega \rho_{0}\right)$ is the $z$-component of wave admittance for plane waves in the medium. Here and in subsequent expressions of this type, $\mathrm{d}_{\underline{K}}$ is an abbreviation for $d k_{x} d k_{y}$ and integration over the infinite $k_{x}, k_{y}$ plane is to be understood. The spectral density functions $a(\underline{K})$ and $b(\underline{K})$ for incoming and outgoing waves, respectively, are defined by eq (4); these are the modal terminal variables, analogous to $\mathrm{a}_{0}$ and $\mathrm{b}_{0}$, for incoming and outgoing $\mathrm{plane}$ waves, referred to the plane $S_{1}(z=0)$ as a phase reference or "terminal" surface. Explicit expressions for $b(\underline{K})$ and $a(\underline{K})$ may be obtained by inversion of the preceding equations:

$$
\begin{aligned}
& b(\underline{K})=\frac{e^{-i \gamma z}}{4 \pi} \int\left(p+\eta^{-1} u_{z}\right) e^{-i \underline{K} \cdot \underline{R}} d \underline{R} \\
& a(\underline{K})=\frac{e^{i \gamma z}}{4 \pi} \rho\left(p-\eta^{-1} u_{z}\right) e^{-i \underline{K} \cdot \underline{R}} d \underline{R}
\end{aligned}
$$

Integrations of this type are to be taken over all values of $x$ and $y$ in any suitable fixed plane $z=$ const. (here $z>z_{1}$ ). $\left(n^{-1}\right.$, which is independent of the space coordinates, is written inside the integral sign merely for convenience.) The spectral functions $b(\underline{K})$ and $a(\underline{K})$ are independent of $z$ (although this may not be immediately apparent in eq (5)), and their phases are automatically referred to the plane $z=0$.

In the absence of incident waves $[a(\underline{K}) \equiv 0], b(\underline{K})$ may be related to $\mathrm{p}$ or to $u_{z}$; in terms of $\mathrm{p}$ on $z=z_{1}$,

$$
b(\underline{K})=\frac{e^{-i \gamma z_{1}}}{2 \pi} \int p\left(\underline{R}, z_{1}\right) e^{-i \underline{K} \cdot \underline{R}} d \underline{R} .
$$


Again in the absence of incident waves, time-average power radiated into $z>0$ is given by

$$
\mathrm{P}_{\mathrm{rad}}=\frac{1}{2} \operatorname{Re} \int \mathrm{p} \overline{\mathrm{u}}_{\mathrm{z}} \mathrm{d} \underline{\mathrm{R}}=\frac{1}{2} \int_{\mathrm{K}<\mathrm{K}} \eta(\mathrm{K})|\mathrm{b}(\underline{\mathrm{K}})|^{2} \mathrm{~d} \underline{\mathrm{K}},
$$

where the superposed bar indicates the complex conjugate and, as indicated by the notation below the integral sign, evanescent waves are excluded from the $\underline{K}$-integration.

The transducer scattering matrix is the detailed expression of the linear behavior of the device under all possible excitations by incident waves. That is, a set of outgoing wave-amplitudes $\left[\mathrm{b}_{0}\right.$ and $\left.\mathrm{b}(\underline{\mathrm{K}})\right]$ will be determined linearly by a set of incident wave-amplitudes $\left[\mathrm{a}_{0}\right.$ and $\left.\mathrm{a}(\underline{K})\right]$, and we write this in the form

$$
\begin{aligned}
\mathrm{b}_{0} & =\mathrm{S}_{00} \mathrm{a}_{0}+\int \mathrm{S}_{01}(\underline{\mathrm{K}}) \mathrm{a}(\underline{\mathrm{K}}) \mathrm{dK}, \\
\mathrm{b}(\underline{\mathrm{K}}) & =\mathrm{S}_{10}(\underline{\mathrm{K}}) \mathrm{a}_{0}+\int \mathrm{S}_{11}\left(\underline{\mathrm{K}}, \underline{\mathrm{K}}^{\prime}\right) \mathrm{a}\left(\underline{K}^{\prime}\right) \mathrm{d} \underline{K}^{\prime},
\end{aligned}
$$

thereby defining the scattering matrix for the transducer considered. [It is convenient and seems appropriate to use the term "matrix" here even though one must think of rows and columns labeled both by discrete indices $(0,1)$ and by indices $\left(k_{x}, k_{y}\right)$ having continuous ranges.] Evidently, the functions $\mathrm{S}_{01}$ and $\mathrm{S}_{10}$ respectively embody the receiving properties and the radiating properties of the transducer; $\mathrm{S}_{00}$ is essentially an ordinary reflection coefficient expressing mismatch at the transducer input, and $S_{11}$ is the kernel of the transformation expressing the scattering (into $z>0$ ) of waves incident on the transducer from the right.*

*Equation (8) provides only a "one-side" description of a transducer. A complete plane-wave scattering-matrix description may be obtained by "enclosing" the transducer between two reference planes and considering incident and emergent spectra on both planes. However, in all the problems considered or mentioned in this paper, a one-side (right-or left-side) description is all that is needed for any one transducer. 
Let us examine the definitions of $\mathrm{S}_{01}$ and $\mathrm{S}_{10}$ (the quantities that will receive the most attention) and restate them somewhat more physically.

We note that, according to eq (5), an incident plane wave with $\mathrm{p}=\mathrm{A} \exp (\underline{i k} \cdot \underline{r}) / 2 \pi$ corresponds to the delta-function spectrum $a\left(\underline{K}^{\prime}\right)=A \delta\left(k_{x}^{\prime}-k_{x}\right) \delta\left(k_{y}^{\prime}-k_{y}\right)$; putting this spectrum in eq $(8 \mathrm{a})$, we see that $\mathrm{S}_{01}(\underline{K})$ represents the received signal $\mathrm{b}_{0}$ as a function of direction of incident plane waves, normalized to $A=1$.

According to eq $(8 \mathrm{~b}), \mathrm{S}_{10}(\underline{K})$ represents the spectrum of outgoing waves under the conditions $a(\underline{K}) \equiv 0, a_{0}=1$. Hence, from eq (6),

$$
S_{10}(\underline{K})=\frac{e^{-i \gamma z_{1}}}{2 \pi a_{0}} \int p\left(\underline{R}, z_{1}\right) e^{-i \underline{K} \cdot \underline{R}} d \underline{R},
$$

that is, $S_{10}(\underline{K})$ may be defined in terms of the Fourier transform of the pressure field obtaining on the plane $z=z_{1}$ in the absence of incident waves, normalized to $a_{0}=1$. (Here $z_{1}$, and in the next paragraph $z_{2}$, represent any planes "in front of" the considered transducer.)

If we multiply eq $(2-9 a)$ by $\exp \left(i \gamma z_{1}\right)$, take the inverse Fourier transform, and evaluate for $z=z_{2}$, we obtain

$$
p\left(\underline{R}, z_{2}\right)=\frac{a_{0}}{2 \pi} \int\left[S_{10}(\underline{K}) e^{i \gamma z_{2}}\right] e^{i \underline{K} \cdot \underline{R}} d \underline{K} .
$$

This exhibits $\mathrm{p}\left(\underline{\mathrm{R}}, \mathrm{z}_{2}\right)$ as a functional of $\mathrm{S}_{10}(\underline{\mathrm{K}})$. (To evaluate $p\left(\underline{R}, z_{2}\right)$ by numerical calculation one would naturally use the fast Fourier transform.)

It is an important convenience to have a more compact formulation of eq (8). We can secure this by introducing function vectors and by making more use of matrix-algebraic concepts. We first define the column matrices

$$
\left(\begin{array}{c}
a_{0} \\
\hat{a}
\end{array}\right),\left(\begin{array}{c}
b_{0} \\
\hat{b}
\end{array}\right)
$$


in which $\hat{a}$ and $\hat{b}$ may themselves be regarded as column matrices corresponding to the functions $a(\underline{K})$ and $b(\underline{K})$. That is to say, the elements of these column matrices are labeled or indexed according to the values of $K$ and have the values $a_{s}(\underline{K})$ and $b(\underline{K})$, respectively. The transformation from the set of incident waves to the set of emergent waves is now written

$$
\left(\begin{array}{l}
b_{0} \\
\hat{b}
\end{array}\right)=\left(\begin{array}{ll}
s_{00} & \hat{s}_{01} \\
\hat{S}_{10} & \hat{s}_{11}
\end{array}\right)\left(\begin{array}{c}
a_{0} \\
\hat{a}
\end{array}\right)
$$

Here $\mathrm{S}_{00}, \hat{\mathrm{S}}_{01}, \hat{\mathrm{S}}_{10}$, and $\hat{\mathrm{S}}_{11}$ may be thought of as point, row, column, and square submatrices, respectively, in a partioning of a grand matrix $\hat{S}$ representing the whole transformation. On performing the implied matrix multiplication, we obtain

$$
\begin{aligned}
\mathrm{b}_{0} & =\mathrm{S}_{00} \mathrm{a}_{0}+\hat{\mathrm{S}}_{01} \hat{\mathrm{a}} \\
\hat{\mathrm{b}} & =\hat{\mathrm{S}}_{10} \mathrm{a}_{0}+\hat{\mathrm{S}}_{11} \hat{\mathrm{a}} .
\end{aligned}
$$

The various kinds of products, such as $\hat{\mathrm{S}}_{01} \hat{\mathrm{a}}$ and $\hat{\mathrm{S}}_{11} \hat{\mathrm{a}}$, appearing here are defined by comparison with eq (8).

Transducers may be classified as reciprocal, antireciprocal,* or non-reciprocal, in accordance with the following definitions: In the reciprocal and the antireciprocal cases, the receiving characteristic and the transmitting characteristic are subject to

$$
n_{0} S_{01}(\underline{K})= \pm n(\underline{K}) S_{10}(-\underline{K})
$$

"We use the term "antireciprocal" in extension of its use for 2 -ports by McMillan [23]. An antireciprocal 2-port is essentially what is identified by the more recent term "gyrator." 
with the upper and the lower sign, respectively.* "In both these cases the scattering function $\mathrm{S}_{11}$ will be subject to

$$
\gamma_{K} S_{11}(\underline{K}, \underline{L})=\gamma_{L} S_{11}(-\underline{L},-\underline{K}) \text {, }
$$

where $\gamma_{K}$ denotes $\gamma$ as a function of $k$. If these conditions do not apply, we may call the transducer non-reciprocal. [Eqs 11 (with the plus sign in eq $11 \mathrm{a}$ ) are closely analogous to the reciprocity relations in the plane-wave scattering matrix description of antennas [12].]

Yaghiian [13] provides derivations of eqs (11) and a basic discussion of their relationship to the form of reciprocity relations given in the classical papers of Foldy and Primakoff [14, 15]. We mention here the following implications of eqs (11): (1) Eq (11a) implies the electroacoustic reciprocity theorem discussed by Foldy and Primakoff [14, eq 51] and others. (2) Eq (11a) implies eq (15) (below). (3) Eqs (11) holding for each of two transducers in a transmission system imply the relation $\eta_{0}^{\prime} M_{21}= \pm n_{0} M_{12}$ for the elements of the scattering matrix of the system 2-port (eq 3-10). Except for the possible occurrence of the minus sign, this is the normal expression of reciprocity for 2 -ports with lead characteristic impedances not necessarily equal [16].

We note that $p(\underline{r})$ is given asymptotically at large distances $r$ by

$$
p(\underline{r}) \sim-i k|\cos \theta| S_{10}(\underline{R k / r}) a_{0} e^{i k r} / r
$$

*The occurrence of the argument $-K$ in one side of eq (11a) means that the equation relates ratiating and receiving characteristics in the line of a given propagation vector $k$ (if an outgoing spectral component has propagation vector $k^{-}$, the corresponding incoming plane wave has propagation véctor - 
the angle $\theta$ introduced here is the polar angle of $\underline{r}$ relative to the $z$-axis. We have written $\underline{R k} / \mathrm{r}$ for the argument of $\mathrm{S}_{10}$; if we introduce spherical coordinates for $\underline{r}$ such that $x=r \sin \theta \cos \phi, y=r \sin \theta \sin \phi, z=r \cos \theta$, we see that $S_{10}$ is expressed as a function of the angular coordinates of $\underline{r}$.

Another useful asymptotic quantity, here called the "effective directivity function" and denoted by $\mathrm{D}_{e}$, is defined as

$\mathrm{D}_{\mathrm{e}}=\frac{\text { power radiated per steradian as a function of direction }}{\text { (net power input to transducer) } /(4 \pi)}$

(The adjective "effective" is used because in this definition $\mathrm{D}_{\mathrm{e}}$ is referred to input power, so that $\mathrm{D}_{\mathrm{e}}$ is not merely relative, but includes effects of internal power losses.) With the aid of eqs (2) and (12), $\mathrm{D}_{\mathrm{e}}$ is found to be given in terms of $\mathrm{S}_{00}$ and $\mathrm{S}_{10}$ by

$$
D_{e}(\theta, \phi)=\frac{4 \pi Y_{0} k^{2} \cos ^{2} \theta\left|S_{10}(\underline{R} k / r)\right|^{2}}{n_{0}\left(1-\left|S_{00}\right|^{2}\right)},
$$

where $Y_{0}$ is the specific acoustic admittance $\left(=\mathrm{k} / \omega \rho_{0}=1 / \mathrm{c} \rho_{0}\right)$. We emphasize that both internal power loss and back radiation (that into $z<0$ ) may occur. Such losses show up in diminished magnitude of $\mathrm{S}_{10}$; eq (13) remains valid and applicable. Further, it can be shown that $\mathrm{D}_{\mathrm{e}}$ is invariant to the insertion or adjustment of a lossless ("2-port") component at the transducer input.

The counterpart of $\mathrm{D}_{\mathrm{e}}$ for a transducer functioning in a receiving mode is the effective area $\sigma_{e}$, defined as $\mathrm{P}_{A} / \mathrm{S}$, where $\mathrm{P}_{\mathrm{A}}$ is the available power at the transducer terminals and $S$ is the power density per unit area in a plane wave 
incident on the transducer from a given direction. In the present framework one finds

$$
\sigma_{e}(\theta, \phi)=\frac{4 \pi^{2} n_{0}\left|S_{01}(\underline{K})\right|^{2}}{Y_{0}\left(1-\left|S_{00}\right|^{2}\right)} .
$$

Here $\theta$ and $\phi$ are the direction angles of the direction from which the incident wave comes. The quantity $\sigma_{\mathrm{e}}$ has the same invariance property as does $D_{e}$. In the event that the transducer is reciprocal or antireciprocal, in the sense of eq (11a), then the relation

$$
D_{e}(\theta, \phi)=4 \pi \sigma_{e}(\theta, \phi) / \lambda^{2}
$$

holds. The analogous relation is well known in antenna theory.

Thus far we have been concerned with the description of a single transducer. In a sense, a single transducer by itself can be of no interest. It is obviously important to consider the interaction of two transducers coupled through the acoustic medium, forming a "transmission system." This is done in the next section, with emphasis upon interaction at arbitrary distances.

\section{SCATTERING-MATRIX ANALYSIS OF COUPLED TRANSDUCERS}

We consider a transmission system consisting of a radiating system and a receiving system operating in a given free fiuid.

For the description of the active terminal, we apply eq $(2-10)$ direct $1 y$ :

$$
\begin{aligned}
& \mathrm{b}_{0}=\mathrm{S}_{00} \mathrm{a}_{0}+\hat{\mathrm{S}}_{01} \hat{\mathrm{a}} \\
& \hat{\mathrm{b}}=\hat{\mathrm{S}}_{10} \mathrm{a}_{0}+\hat{\mathrm{S}}_{11} \hat{\mathrm{a}} .
\end{aligned}
$$


These equations are set up with reference to terminal surfaces $S_{0}$ and $S_{1}$, the latter being at $z=0$ in the coordinate system Oxyz (fig. 1).

Using primes to distinguish quantities associated with the passive terminal, we write

$$
\begin{aligned}
& \mathrm{b}_{0}^{\prime}=\hat{s}_{00}^{\prime} \mathrm{a}_{0}^{\prime}+\hat{\mathrm{s}}_{01}^{\prime} \hat{\mathrm{a}}^{\prime}, \\
& \hat{\mathrm{b}}^{\prime}=\hat{\mathrm{s}}_{10}^{\prime} \mathrm{a}_{0}^{\prime}+\hat{\mathrm{s}}_{11}^{\prime} \hat{\mathrm{a}}^{\prime} .
\end{aligned}
$$

For these equations, the terminal surfaces are $S_{0}^{\prime}$ and $S_{1}^{\prime}$, the latter being $z=d$ in the coordinate system Oxyz. Note that these equations describe receiving, transmitting, and scattering characteristics for directions in the $z<0$ hemisphere, with the transducer in its desired orientation. A minor extension of the definitions used in eq (1) is implicit.

The third element of the transmission system under consideration is the section of "waveguide" between the terminal surfaces $S_{1}$ and $S_{1}^{\prime}$. We need the matrix description of this element, too; fortunately, under the simple conditions postulated for the transmission path, we can actually write this matrix explicitly. We can arrive at the needed relations by momentarily considering an axial translation of the terminal surface $S_{1}$ from $z=0$ to $z=d_{1}$, say. From eq $(2-4)$, the new spectral density functions for the outgoing and incoming waves would be simply $b(\underline{K}) \exp \left(i \gamma d_{1}\right)$ and $\mathrm{a}(\mathrm{K}) \exp \left(-{ }^{-i \gamma d_{1}}\right)$, respectively. By taking $d_{1}=d$ and applying the evident joining equations, we obtain

$$
\begin{aligned}
& b(\underline{K}) e^{i \gamma d}=a^{\prime}(\underline{K}), \\
& a(\underline{K}) e^{-i \gamma d}=b^{\prime}(\underline{K}) .
\end{aligned}
$$


These equations are intuitively evident once the underlying conventions are clearly established. Now, with respect to the transmission path as an element of the system, the set of incident waves is represented by $\hat{b}$ and $\hat{b}^{\prime}$ and the set of emergent waves is represented by $\hat{a}$ and $\hat{a}^{\prime}$. Thus, from eqs (3) and (4), the matrix description of this element is

$$
\left(\begin{array}{l}
\hat{a} \\
\hat{a}^{\prime}
\end{array}\right)=\left(\begin{array}{cc}
\hat{0} & \hat{T} \\
\hat{T} & \hat{0}
\end{array}\right)\left(\begin{array}{l}
\hat{b} \\
\hat{b}^{\prime}
\end{array}\right),
$$

where the elements of $\hat{\mathrm{T}}$ are

$$
\mathrm{T}(\underline{K} ; \underline{L})=\delta\left(k_{x}-l_{x}\right) \delta\left(k_{y}-l_{y}\right) e^{i \gamma(\underline{K}) d} .
$$

This is equivalent to the two separate transformations

$$
\begin{aligned}
& \hat{a}=\hat{T} \hat{b}^{\prime}, \\
& \hat{a}^{\prime}=\hat{T} \hat{b} .
\end{aligned}
$$

We are now in a position to obtain a complete formal solution for the behavior of the transmission system under consideration. That is, we can obtain expressions for both $\mathrm{b}_{0}$ and $\mathrm{b}_{0}^{\prime}$, valid at arbitrary distances and including the effects of multiple reflections. (We can also formally determine the field in the transmission path.) The procedure involves only straightforward combination of eqs (1), (2), and (5), using rules of matrix algebra. An inspection of the following intermediate results will make the final results more intelligible. We assume that the receiving transducer is terminated with a passive, reflectionless load. Then we find first

$$
\hat{\mathrm{a}}=\hat{\mathrm{T}} \hat{\mathrm{b}}^{\prime}=\hat{\mathrm{TS}}_{11}^{\prime} \hat{\mathrm{a}}^{\prime}=\hat{\mathrm{TS}} \hat{\mathrm{S}}_{11}^{\prime} \hat{\mathrm{T}} \hat{\mathrm{b}} \text {. }
$$


The operator $\hat{\mathrm{TS}}_{11}^{\prime} \hat{\mathrm{T}}$ appearing here is the description of the receiving system, as a passive scattering object, referred to the reference $\mathrm{plane} \mathrm{S}_{1}$ of the transmitting transducer. Since this operator recurs frequently, we denote it briefly by $\hat{R}^{\prime}$. Substituting eq (6) in eq (1), we obtain

$$
\hat{b}=\hat{S}_{10} a_{0}+\hat{S}_{11} \hat{R}^{\prime} \hat{b} \text {, }
$$

which (at least when written out more fully) is seen to be an integral equation determining $\hat{b}$. (It may be identified as an inhomogeneous integral equation of the second kind.) The solution may be indicated formally by writing

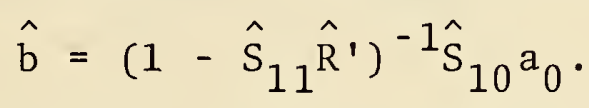

This gives us the spectrum of outgoing waves in the transmission path; it includes both the simple plane waves and the evanescent waves. ( $\mathrm{a}$ is now determined by eq 6 , and $p(\underline{r})$ and $u_{z}(\underline{r})$ are determined by eq 2-4.) of several available constructive procedures for the solution of the basic integral equation, the Liouville-Neumann method of successive substitutions seems most appropriate in the present physical context. This leads to a representation of the inverse operator in eq (8) in a series [analogous to the geometric series for the algebraic expression $1 /(1-x)]$; the result is

$$
\hat{b}=\left[\hat{1}+\hat{S}_{11} \hat{R}^{\prime}+\left(\hat{S}_{11} \hat{R}^{\prime}\right)^{2}+\cdots-\hat{S}_{10} a_{0}\right. \text {. }
$$

The successive terms in this series correspond to successive round-trip multiple reflections between the transmitting and the receiving transducers. Convergence must be expected on physical grounds. The rapidity of convergence 
depends upon the "smallness" of the product $\hat{S}_{11} \hat{R}^{\prime}$, and it worth noting that this product depends upon both $\mathrm{S}_{11}$ and $\mathrm{S}_{11}$ (as well as upon the distance between the transducers). We complete this analysis by calculating the scattering matrix of the "system 2-port," which has its terminals at $S_{0}$ and $S_{0}^{\prime}$ and is defined by the equations

$$
\left.\begin{array}{l}
b_{0}=M_{11} a_{0}+M_{12} a_{0}^{\prime}, \\
b_{0}^{\prime}=M_{21} a_{0}+M_{22} a_{0}^{\prime} \cdot
\end{array}\right\}
$$

(The properties of a transmission system are often conveniently embodied in this form). Inasmuch as we have put $a_{0}^{\prime}=0$, solving for $b_{0} / a_{0}$ and for $b_{0}^{\prime} / a_{0}$ yields directly

$$
\begin{aligned}
& M_{11}=S_{00}+\hat{S}_{01} \hat{R}^{\prime}\left(1-\hat{S}_{11} \hat{R}^{\prime}\right)^{-1} \hat{S}_{10}, \\
& M_{21}=\hat{S}_{01}^{\prime} \hat{T}\left(1-\hat{S}_{11} \hat{R}^{\prime}\right)^{-1} \hat{S}_{10} .
\end{aligned}
$$

A similar alternative solution with $a_{0}=0$ and $a_{0}^{\prime} \neq 0$ yields

$$
\begin{aligned}
& M_{22}=S_{00}^{\prime}+\hat{S}_{01}^{\prime} \hat{R}\left(1-\hat{S}_{11}^{\prime} \hat{R}\right)^{-1} \hat{S}_{10}^{\prime}, \\
& M_{12}=\hat{S}_{01} \hat{T}\left(1-\hat{S}_{11}^{\prime} \hat{R}\right){ }^{-1} \hat{S}_{10}^{\prime},
\end{aligned}
$$

where $\hat{\mathrm{R}} \equiv \hat{\mathrm{TS}}_{11} \hat{\mathrm{T}}$. (Formally identical equations hold in the purely electromagnetic (antenna) context [17].)

Although the kernel in the basic integral equation (and iterated in eq 9) may indeed be complicated, we emphasize that the above analysis is not completely formal. It provides a basis for further useful analysis, some of which is described in 55 and in an appendix to this paper; complete analytical solutions can be obtained in interesting special cases. 
In the measurement technique to described in $\S 4$, we assume that the effects of reflections between transducers have been minimized and may be neglected. (This would not seem to be an unusual requirement. What may be unusual is that the measurement technique to be described in $\S 5$ provides a means of coping with proximity effects and with multiple reflections between transducers.) When such reflections are omitted, eqs (12) and (13) become $\mathrm{M}_{21}=\hat{\mathrm{S}}_{01}^{\prime} \hat{\mathrm{TS}}_{10}$ and $M_{22}=S_{00}^{\prime}$, respectively. If the (passive) termination on the receiving transducer has reflection coefficient $\Gamma_{L}$, we obtain from eq (10)

$$
\mathrm{b}_{0}^{\prime}=\mathrm{F}^{\prime} \hat{\mathrm{S}}_{01}^{\prime} \hat{\mathrm{TS}}_{10} \mathrm{a}_{0}
$$

where $F^{\prime}=\left(1-\Gamma_{L_{00}} S^{\prime}\right)^{-1}$ is a circuit "reflection factor." More explicit1y, we have

$$
\mathrm{b}_{0}^{\prime}=\mathrm{a}_{0} \mathrm{~F}^{\prime} \quad \int \mathrm{S}_{01}^{\prime}(\underline{\mathrm{K}}) \mathrm{S}_{10}(\underline{\mathrm{K}}) \mathrm{e}^{\mathrm{i \gamma} \mathrm{d}} \mathrm{dK} .
$$

The integral appearing in this equation is here named the (acoustic) "transmission integral" and is given a special symbol:

$$
\Psi(\mathrm{d})=\int \mathrm{S}_{01}^{\prime}(\underline{K}) \mathrm{S}_{10}(\underline{K}) \mathrm{e}^{i \gamma \mathrm{d}} \mathrm{dK} .
$$

The product $\mathrm{S}_{01}^{\prime} \mathrm{S}_{10}$ in the integrand we call the "spectral coupling product." Equation (15b) is the acoustic analog of the transmission integral employed, e.g., in [1]. (The only formal difference is that in the electromagnetic case, the coupling product is the scalar product of two 2component vectors, which contain polarization information.)

In order to exhibit some of the content of eqs (15a) and ( $15 b$ ) (but not for the present applications) we note that a well-known type of transmission formula, analogous 
to the Friis transmission formula in antenna theory, can be derived from the asymptotic form of eq (15a). The asymptotic form in question is

$$
b_{0}^{i} \sim-2 \pi i k F^{\prime} S_{01}^{i}(0) S_{10}(0) a_{0} e^{i k d} / d \text {. }
$$

If we now calculate the ratio of the available power at the receiving transducer terminals to the net input power at the transmitting transducer terminals, we obtain

$$
\frac{\mathrm{P}_{\mathrm{A}}^{\prime}}{\mathrm{P}_{0}}=\frac{\mathrm{D}_{\mathrm{e}}(0) \sigma_{\mathrm{e}}^{\prime}(0)}{4 \pi \mathrm{d}^{2}}
$$

where $D_{e}(0)$ pertains to the transmitting transducer, $\sigma_{e}^{\prime}(0)$ pertains to the receiving transducer, and we have used eqs $(2-13)$ and $(2-14)$.

We mention one more important result, contained in eq (3-11) (and, similarly, in eq 3-13): The first iterated integral in the Liouville-Neumann series for $\mathrm{M}_{11}$ is

$$
\Phi(\mathrm{d})=\int_{\underline{K}} S_{01}(\underline{K}) e^{i \gamma_{K} d} d \underline{K} \int_{\underline{L}} S_{11}^{\prime}(\underline{K}, \underline{L}) S_{10}(\underline{L}) e^{i \gamma_{L} d} d \underline{L},
$$

where $\gamma_{K}$ denotes $\gamma$ as a function of $K$. This is called the (acoustic) reflection integral. It is the simplest integral involving a reflection or scattering process. It can be interpreted as a basic monostatic sonar equation, which, apart from multiple reflections between target and transceiver, is valid at arbitrary distances. Examples of the use of the purely electromagnetic analog of eq (18) may be found in [12]. 


\section{TRANSVERSE SCANNING AND DECONVOLUTION}

We can now quite easily give the promised analytical basis for determining the coupling product $\mathrm{S}_{01}^{\prime} \mathrm{S}_{10}$ from near-field transverse scanning data. The significance of determining this product was indicated in $\S 1$.

Let the required relative transverse displacement between the transmitting and the receiving transducer be denoted by a transverse displacement $\underline{p}=x_{\underline{e}}+y \underline{e}_{y}$ of the receiving transducer (fig. 1$)$. This requires modification of eq $(3-15 a)$ : by considering the phase $\underline{k} \cdot \underline{r}$ of the waves in the spectrum incident upon the receiving transducer, one readily finds that a phase factor $\exp (\mathbf{i K} \cdot \underline{R})$ must be supplied in the integrand. Equation (3-15a) thus becomes

$$
\mathrm{b}_{0}^{\prime}(\underline{P})=\mathrm{a}_{0} \mathrm{~F}^{\prime} \delta \mathrm{e}^{\mathrm{i} \underline{K} \cdot \underline{P}^{\prime}} \mathrm{S}_{01}^{\prime}(\underline{K}) \mathrm{S}_{10}(\underline{K}) \mathrm{e}^{i \gamma \mathrm{d}} \mathrm{d} \underline{K} \text {. }
$$

Note that the quantity $b_{0}^{\prime}(\underline{p})$ is what is observed in the measurement process; it may or may not be simply related to the pressure $p(\underline{r})$ at the point $\underline{r}=(\underline{P}, d)$. The value of the product $\mathrm{S}_{01}^{\prime} \mathrm{S}_{10}$ in the integrand is what is sought. Inasmuch as eq (1) represents a Fourier integral transformation, its inversion is immediate:

$$
S_{01}^{\prime}(\underline{K}) S_{10}(\underline{K})=\frac{e^{-i \gamma d}}{4 \pi^{2} F^{\prime} a_{0}} \int b_{0}^{\prime}(\underline{P}) e^{-i \underline{K} \cdot \underline{P}} d \underline{p} .
$$

The inversion of eq (1) is appropriately and usefully termed "deconvolution." This is appropriate because both factors, $\mathrm{S}_{01}^{\prime}$ and $\mathrm{S}_{10}$, can be interpreted as Fourier transforms of certain physical fields. It is useful because it helps to emphasize the distinction between eq (2) and the simpler equation representing the definition of $\mathrm{S}_{10}$ (eq 2-9a). 
We note that eq (2) contains the factor $b_{0}^{\prime}(\underline{P}) / a_{0}$; the occurrence of this factor is a characteristic of the measurement methods being described. The full exploitation of eq (2) requires that $b_{0}^{\prime}(\underline{P}) / a_{0}$ be measured correctly in magnitude and relative phase.

Clearly the utility of this result depends upon one's ability to evaluate the transform of the empirically observed $b_{0}^{\prime}(\underline{P})$. In the electromagnetics work, both a twodimensional form of sampling theorem [1] and least-squares fitting have been successfully used [3] to evaluate the required transform of $b_{0}^{\prime}(\underline{P})$ from data taken at the points of a rectangular lattice in the measurement plane. The application of the sampling theorem has become the method of choice, mainly because of the greater ease of computation, and will be described very briefly here.

The essential requirement of the sampling theorem is that the function to be sampled be representable as the Fourier transform of a band-limited function. That $\mathrm{b}_{0}^{\prime}(\underline{\mathrm{P}})$ virtually fulfills this condition may be seen from eq (1): a band-1imit $K_{B}$ somewhat greater than $k$, and a distance $d$, may be chosen so that evanescent waves for all $\mathrm{K}>\mathrm{K}_{\mathrm{B}}$ are assuredly virtually zero in the measurement plane (e.g., with $\mathrm{K}_{\mathrm{B}}=1.05 \mathrm{k}$ and $\mathrm{d}=15 \lambda$, attenuation at the band limit is approximately $260 \mathrm{~dB}$ ). Band-limiting within a smaller spectral region may result from the behavior of the product $\mathrm{S}_{01}^{\prime}(\underline{\mathrm{K}}) \mathrm{S}_{10}(\underline{\mathrm{K}})$ in individual cases. If we assign band limits $\mathrm{k}_{1} \equiv 2 \pi / \lambda_{1}$ and $\mathrm{k}_{2} \equiv 2 \pi / \lambda_{2}$ for $\mathrm{k}_{\mathrm{x}}$ and $\mathrm{k}_{\mathrm{y}}$, respectively, a straightforward generalization of the usual one-dimensional theory [18] enables us to replace the integral in eq (2) by a sum:

$$
S_{01}^{\prime}(\underline{K}) S_{10}(\underline{K})=\frac{e^{-i \gamma d}}{4 k_{1} k_{2} F^{\prime} a_{0}} \sum_{r, s} b_{0}^{\prime}\left(\underline{P}_{r s}\right) e^{-i \underline{K} \cdot \underline{P}} r s .
$$


The vectors $\underline{\mathrm{p}}_{\mathrm{rs}}=\frac{1}{2} \mathrm{r} \lambda_{1} \underline{\mathrm{e}}_{\mathrm{x}}+\frac{1}{2} \mathrm{~s} \lambda_{2} \frac{\mathrm{e}}{\mathrm{y}}_{\mathrm{y}}$ (with $\mathrm{r}, \mathrm{s},=\ldots .-1,0$, $1,2, . .$.$) define the measurement lattice, the quantities$ $\mathrm{b}_{0}\left(\underline{\mathrm{P}}_{\mathrm{rs}}\right)$ are the (complex) values of probe output directly observed at the points of the lattice, and the summation goes over the points of the lattice. According to the sampling theorem, eq, (3) is mathematically exact; that is, if the data [the $b_{0}^{\prime}\left(\underline{P}_{r s}\right)$ ] were complete and exact, the result would be exact. The theorem requires an infinite sum, but in the electromagnetic application we have found that not even all values measurable above noise are needed. An important feature of eq (3) is that the highly efficient algorithm known as the "fast Fourier transform" is rigorously applicable to evaluate the sum [19].

Our antenna measurement experience using this technique indicates that using $\mathrm{k}_{1}=\mathrm{k}_{2}=\mathrm{k}$ is satisfactory as a ruleof-thumb when essentially complete pattern information is desired. These band 1 imits correspond to a $\lambda / 2$ spacing of measurement-1attice points and mean that typically a relatively large number of data are required. Nevertheless, for a measurement lattice comprising a "moderate" number of points, the fast-Fourier-transform computation time is nominal. For example, to obtain complex pattern data in 64 x 64 directions from a $64 \times 64$ input data array, the "in-core" computation time is approximately 1.5 seconds on a CDC 3800 computer. Figure 2 gives a qualitative idea of results obtained in a particular case.

\section{RECEIVED SIGNAL AS A FUNCTION OF DISTANCE AND THE EXTRAPOLATION TECHNIQUE}

The extrapolation technique was described qualitatively in $\S 1$. This technique requires observation of $b_{0}^{\prime} / a_{0}$ as a function of transducer separation distance $d$, which is precisely defined by the choice of reference surfaces $S_{1}$ and $S_{1}^{\prime}$ 


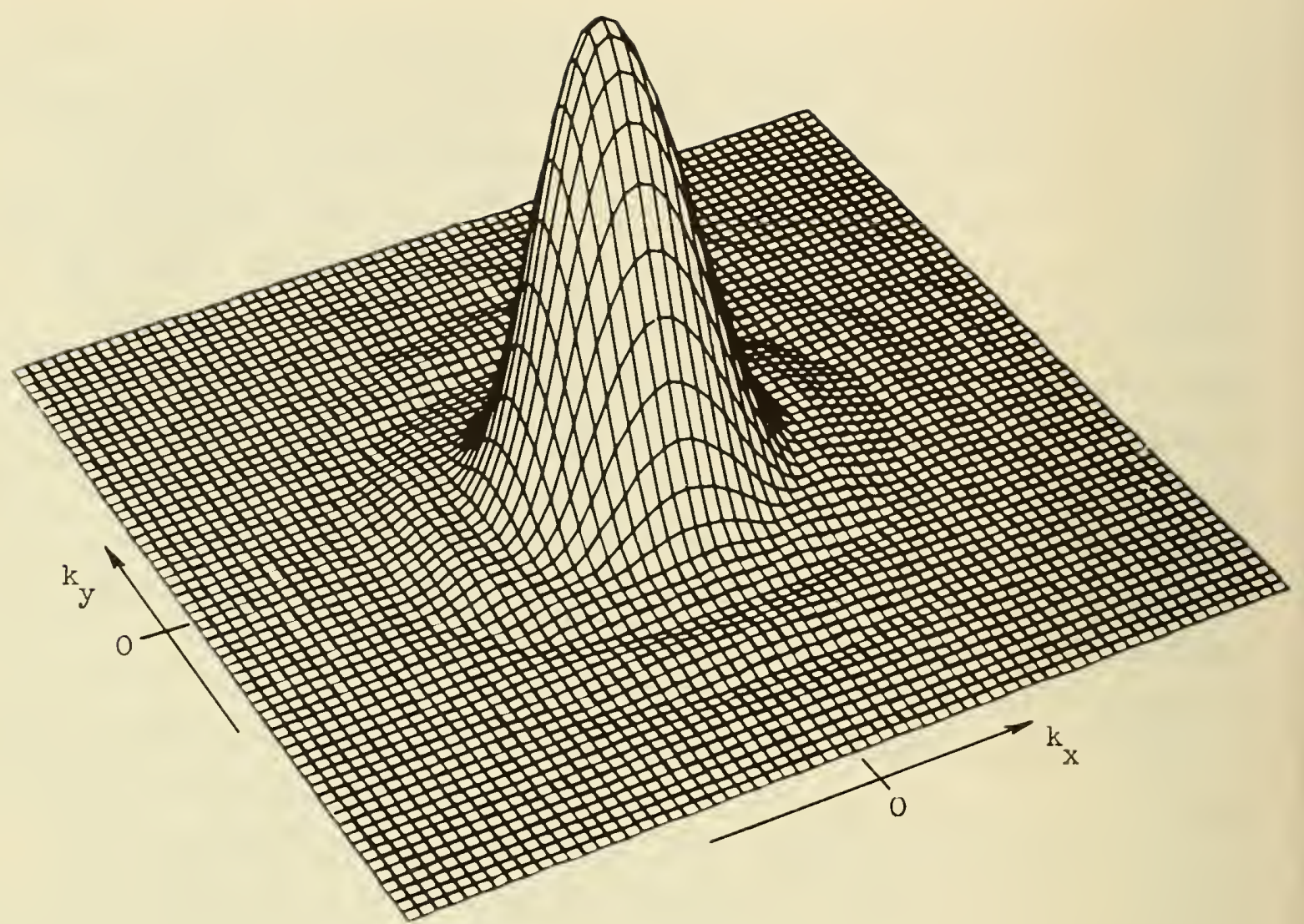

Figure 2. Far electric-field amplitude determined from nearfield data for JPL microwave horn antenna.

Values in $64 \times 64$ directions specified by the angles $\theta, \phi$ are plotted above the points $k_{x}=k \sin \theta \cos \phi$, $k_{y}=k \sin \theta \sin \phi$ and connected by straight-1ine segments.

associated with the respective transducers (fig. 1). From the scattering equations for the system two-port, we obtain the expression

$$
\mathrm{b}_{0}^{\prime}=\mathrm{a}_{0} \mathrm{M}_{21} /\left(1-\mathrm{M}_{22} \Gamma_{\mathrm{L}}\right)
$$

which is a precise and complete version of eq (3-15a). Expressions for the elements $\mathrm{M}_{21}$ and $\mathrm{M}_{22}$ are given in 
eqs (3-12) and (3-13). From these expressions, by a rather lengthy process, one finds for eq (1) a series representation of the form

$$
b_{0}^{\prime}=a_{0} F^{\prime} \sum_{p=0}^{\infty} \frac{\exp [i(2 p+1) k d]}{d^{2 p+1}} \sum_{q=0}^{\infty} A_{p q} d^{-q},
$$

where $F^{\prime}$ is as defined in connection with eq (3-15a). We observe that the subseries of terms with a given p represents the contribution of energy which has experienced $2 \mathrm{p}$ reflections (or made $2 p+1$ transits) between transducers. In particular, the series with $\mathrm{p}=0$ involves no reflections and is the expansion of the transmission integral (eq 3-15b):

$$
\Psi(d)=\frac{e^{i k d}}{d}\left(A_{00}+A_{01} d^{-1}+A_{02} d^{-2}+\ldots\right) .
$$

(Since this expansion is in powers of $1 / d$, it is of asymptotic type; but since it is convergent under mild restrictions, it is not merely asymptotic. The derivation and convergence of this expansion are considered in an appendix). Further, as shown in the appendix (or by comparison with eq 3-16), we see that

$$
A_{00}=-2 \pi i k S_{01}^{\prime}(0) S_{10}(0)
$$

Hence determination of the leading coefficient in eq (2) is tantamount to the determination of the (on-axis) value of the spectral coupling product. The basic idea of what we may call the conventional measurement method is simply to have d large enough to make other terms negligible compared to the leading term of the series. The basic idea of the extrapolation technique is to observe $b_{0}^{\prime}$ as a function of $d$ and to fit this function with as many terms of eq (2) as may be significant, and so to determine a good value for $A_{00}$ in particular. 
A very brief discussion of the application of this basic idea in antena measurements may be of interest and inat be indicative for acoustic applications.

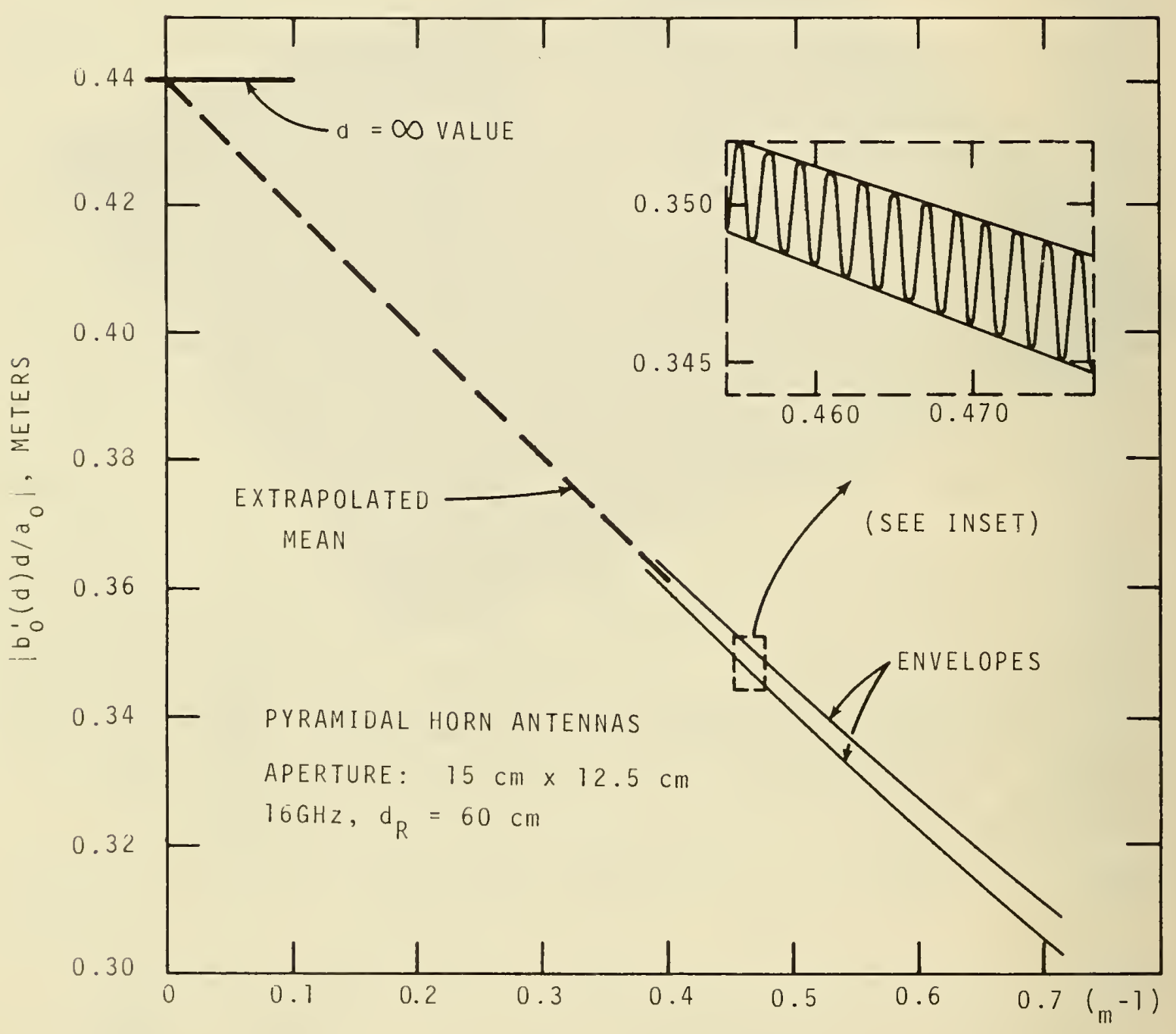

$l / d, d=$ SEPARATION DISTANCE IN METERS

Figure 3. Character of data and extrapolation.

The extrapolation technique has permitted determination of $A_{00}$ (at a given and high level of precision) from measurements made at greatly reduced distances: $d \sim \mathrm{d}_{\mathrm{R}}$ rather 
than $d \gg d_{R}$. The general character of data and of the extrapolation is indicated in figure 3 . The inset enlargement shows a sample of the small oscillations of the received signa1. These oscillations are of approximate period $\lambda / 2$ and may be interpreted as due to multiple reflections. In eq (2), this is represented by interference between terms with $\mathrm{p}=0$ and smaller terms of higher order. In the fitting process, the values of $\left|b_{0}^{\prime}(d) d / a_{0}\right|^{2}$ were averaged locally, and the averaged curve was fitted with a 3 or 4 term polynomial in $1 / \mathrm{d}$. This procedure determines $\left|\mathrm{A}_{00}\right|$ (which ordinarily would be sufficient in acoustic applications); the phase of $\mathrm{A}_{00}$ was determined separately. 


\section{APPENDIX: EXPANSION OF $\mathrm{b}_{0}^{\prime}(\mathrm{d}) / \mathrm{a}_{0}$}

The main result in this appendix is the series expansion (in powers of $1 / d$ ) of the transmission integral, which is the most important part of eq (5-2). The origin of the complete expression of eq (5-2) will be considered very briefly.

This work was stimulated by the work of Wacker [6] on the corresponding purely electromagnetic problem, but the procedure used here is substantially different from that of Wacker.

For our purposes the mechanical equations of motion for small vibrations in an electroacoustic transducer may be presented briefly in the form

$$
-i \omega \rho_{m}^{o} \underline{u}=\nabla \cdot[\underline{\underline{\underline{\underline{c}}}}: \underline{\underline{s}}]+\underline{f}_{1} .
$$

Here $\rho_{\mathrm{m}}^{\mathrm{O}}$ is quiescent mass density, $\underline{u}$ is particle velocity, $\underline{\underline{\underline{c}}}$ is the Hooke's tensor, $\underline{\underline{s}}$ is the strain tensor, and $\underline{f}_{1}$ is the total body force other than that due directly to $\underline{\underline{s}}$. All these quantities are functions of position within the region $V$ of the transducer. The body force $\underline{f}_{1}$ in general includes piezoelectric, piezomagnetic, and Lorentz forces. The first term on the right in eq (1) is more specifically

$$
i, j, k, l \stackrel{e}{i}_{i} \frac{\partial}{\partial x_{j}}\left(c_{i j k \ell} s_{k \ell}\right),
$$

where $\underline{\underline{s}}$ is expressed in terms of $\underline{u}$ by

$$
s_{k \ell}=\frac{i}{2 \omega}\left(\frac{\partial u_{k}}{\partial x_{\ell}}+\frac{\partial u_{\ell}}{\partial x_{k}}\right) \text {. }
$$

(Our notation is coordinated with that of Yaghjian [13] and that of Primakoff and Foldy [15]. For details of the equations of motion see especially Yaghjian.) 
Our first task is to reduce the problem represented by eq (1) formally to that of prescribed sources operating in a homogeneous fluid and to obtain expressions for the plane-wave spectra in the reduced problem. To this end we add and subtract terms in eq (1) to bring it into the form

$$
-i \omega \rho_{0} \underline{u}-\nabla \cdot[\underline{\underline{c}} 0: \underline{\underline{s}}]=\underline{F} \text {, }
$$

where $\rho_{0}$ and $\underline{\underline{\underline{w}}}{ }_{0}$ are respectively the density and the Hooke's "tensor" for the ambient medium, and $\underline{F}$ is a total equivalent body force given by

$$
\underline{F}=\nabla \cdot[(\underline{\underline{\underline{c}}}-\underline{\underline{c}} \underline{\underline{\underline{c}}}): \underline{\underline{s}}]+i \omega\left(\rho_{m}-\rho_{0}\right) \underline{u}+\underline{f}_{1} \cdot
$$

The essential features of this rearrangement are that the constants in the left-hand side are those of the ambient medium and that $\underline{F}$, though unknown in the region $V$, does vanish outside $V$. Now the Hooke's tensor for the ambient medium is equivalent to the scalar $\rho_{0} c^{2}$, the reciprocal of the compressibility of the fluid. Taking the divergence of both sides of eq (3) and simplifying the elastic force term on the left-hand side we obtain the scalar equation

$$
-i \omega \rho_{0} \nabla \cdot \underline{u}+\frac{\nabla^{2} \nabla \cdot \underline{u} \rho_{o} c^{2}}{i \omega}=Q \text {, }
$$

where $Q=\nabla \cdot \underline{F}$ is the equivalent scalar source distribution. Equation (4) represents essentially the desired formal reduction to a problem of prescribed sources in a homogeneous medium. If we set $p(\underline{r})=\rho_{0} c^{2} \nabla \cdot \underline{u} / i \omega$, eq (4) takes the simpler form

$$
\nabla^{2} p+k^{2} p=Q \text {, }
$$

where $k^{2}=\omega^{2} / c^{2}$. Furthermore, for points outside $V$, the function $p(\underline{r})$ is by eq $(2-2)$ identical to the acoustic pressure $p(\underline{r})$. We make essential use of this fact in a moment. 
The solution of eq (5) is well known [20] to be

$$
p(\underline{r})=\frac{1}{4 \pi} \int_{V} Q\left(\underline{r}^{\prime}\right) \frac{e^{i k\left|\underline{r}-\underline{r}^{\prime}\right|}}{\left|\underline{r}-\underline{r}^{\prime}\right|} d \underline{r}^{\prime} .
$$

Next, we need the plane-wave representation of the spherical wave [21] in eq (6),

$$
\frac{e^{i k\left|\underline{r}-\underline{r}^{\prime}\right|}}{\left|\underline{r}-\underline{r^{\prime}}\right|}=\frac{i}{2 \pi} \int \gamma^{-1} e^{i \underline{k} \cdot\left(\underline{r}-\underline{r}^{\prime}\right)} d \underline{K},
$$

where $k_{z}=+\gamma$ or $-\gamma$ according as $z>z^{\prime}$ or $z<z^{\prime}$, and the notation for the integral is that established in $\S 2$. Considering a finite region of integration $V$, taking $z$ greater than the maximum of $z^{\prime}$, substituting eq (7) in (6), and interchanging the order of integrations, we obtain for $p(\underline{r})$ the representation

$$
p(\underline{r})=\frac{i}{8 \pi^{2}} \int_{\underline{K}} \gamma^{-1} e^{i \underline{k} \cdot \underline{r}} d \underline{K} \int_{V} Q\left(\underline{r}^{\prime}\right) e^{-i \underline{k} \cdot \underline{r}^{\prime}} d \underline{r}^{\prime},
$$

wherein $\mathrm{k}_{z}=+\gamma$. By comparison with eq $(2-4 \mathrm{a})$, we see that this expression contains the spectrum of $p(\underline{r})$ for points to the right of $\mathrm{V}$.

Let us apply eq (8) to the transmitting transducer, shown on the left in figure 1 and (even more schematically) in figure 4. If the field is produced by excitation of the transducer at its electrical terminals by an incident wave of amplitude $a_{0}$ and if we consider points with $z>z_{1}$, then the normalized spectrum is just what we have denoted by $\mathrm{S}_{10}$ :

$$
\underline{S}_{10}(\underline{K})=\frac{1}{4 \pi a_{0} \gamma} \int_{V} Q(\underline{r}) e^{-i \underline{k} \cdot \underline{r}} d \underline{r} \text {. }
$$

Here the integration goes over the finite region $V$, and the variable of integration, $\underline{r}$, is measured from 0 . 


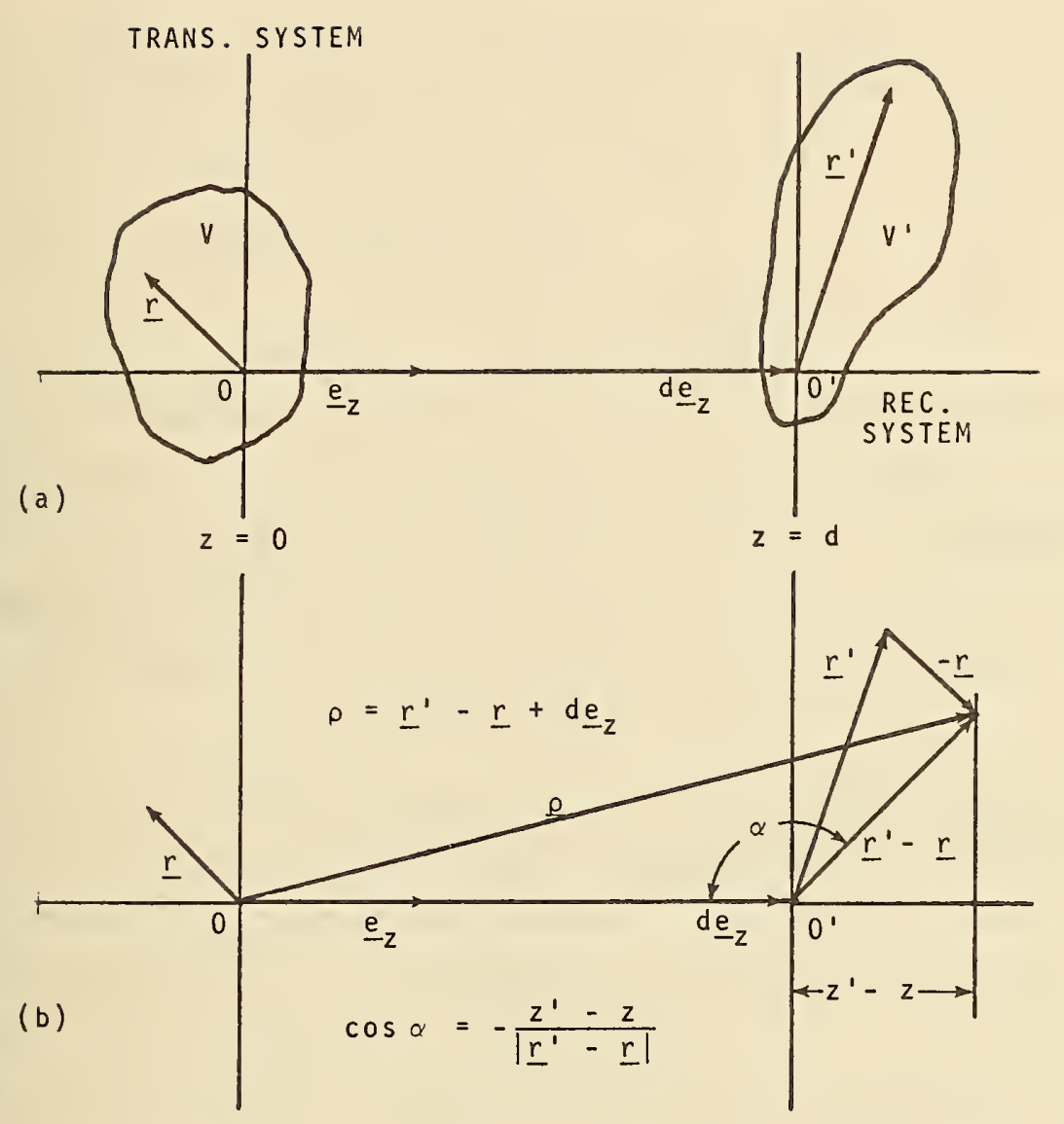

Figure 4. (a) Domains of $Q$ and $Q^{\prime a}$; (b) composition of the vector $\underline{\rho}$.

In order to set up the transmission integral, we need also a representation for the receiving characteristic of the receiving transducer. We may obtain this readily and with great generality from the transmitting characteristic of the (hypothetical) transducer adjoint to the given receiving transducer, using the generalized or adjoint reciprocity relation for electroacoustic transducers, given by Yaghjian [13]. The relation in question reads

$$
n_{0}^{\prime} S_{01}^{\prime}(\underline{K})=\frac{\gamma}{\omega \rho_{0}} S_{10}^{a}(-\underline{K}) \text {, }
$$


where the primes refer to the transducer on the right and $S_{10}^{a}$ refers to the adjoint of that transducer. Now, $S_{10}^{a}$ is given by

$$
S_{10}^{a}(\underline{K})=\frac{i}{4 \pi a_{0}^{\prime} \gamma} \int_{V^{\prime}} Q^{\prime a}\left(\underline{r}^{\prime}\right) e^{-i \underline{k}}{ }^{-} \cdot \underline{r}^{\prime} d \underline{r}^{\prime},
$$

where the integration goes over the finite volume $\mathrm{V}^{\prime}$ and the variable of integration, $\underline{r}^{\prime}$, is measured from $0^{\prime}$ (the point $(0,0, d))$. Equation (11) is similar to eq (9); $\underline{\mathrm{k}}^{-}=\underline{\mathrm{K}}-\underline{\mathrm{r}}_{2}$ appears since here we are interested in the spectrum to the left of the sources. Combining the last two equations, we obtain

$$
S_{01}^{\prime}(K)=\frac{i}{4 \pi a_{0}^{\prime} n_{0} w \rho_{0}} \int Q^{\prime a}\left(\underline{r}^{\prime}\right) e^{+i \underline{k} \cdot \underline{r}^{\prime}} d \underline{r}^{\prime} .
$$

We can now turn to the evaluation of the transmission integral, eq (3-15b). We substitute the expressions from eqs (9) and (12) into the transmission integral and arrange the integrations as follows.

$$
\Psi(\mathrm{d})=C_{1} \int_{V} \int_{V^{\prime}} d \underline{r} d \underline{r}^{\prime} Q(\underline{r}) Q^{\prime a}\left(\underline{r}^{\prime}\right) \int_{\underline{K}} \gamma^{-1} e^{i \underline{k}} \cdot \underline{\rho} d \underline{K} .
$$

Here $C_{1}$ absorbs all constant multipliers and $\underline{\rho} \equiv \underline{r}^{\prime}-\underline{r}+\underline{d e}_{z}$. We further let $\rho=\sqrt{\mathrm{d}^{2}-2 \mathrm{~d} \Delta \mathrm{r} \cos \alpha+(\Delta \mathrm{r})^{2}}$, where $\Delta r \equiv\left|\underline{r}^{\prime}-\underline{r}\right|$ and $\alpha$ is defined in figure 4. By applying eq (7), we find that the K-integral in eq (13) is proportional to

$$
g(d)=e^{i k \rho} / \rho \text {. }
$$

The analytical properties of this expression as a function of (complex) d are decisive for the behavior of $\Psi(d)$ itself. g(d) has an essential singularity at $\infty$, which we remove by multiplication by $\exp (-i k d)$; it follows from the behavior of 
$\rho$ as a function of $d$ that the product $\exp [i k(\rho-d)] / \rho$ is analytic in the extended plane for $|d|>\Delta r$. This means that the product is representable by a Laurent series containing only negative powers of $d$,

$$
\exp [i k(\rho-d)] / \rho=\sum_{n=1}^{\infty} f_{n} d^{-n},
$$

convergent for $d>\Delta r$. The $f_{n}$ are functions of $\underline{r}$ and $\underline{r}^{\prime}$; the first of these functions, which is of special interest, is easily found to be

$$
f_{1}=\exp \left[i k\left(z^{\prime}-z\right)\right]
$$

To obtain the desired evaluation of the transmission integral, we substitute eq (15) into (13) and integrate term-by-term. The result is the expansion shown in eq (5-3). Provided that

$$
\mathrm{d}>(\Delta \mathrm{r})_{\max }
$$

where $(\Delta \mathrm{r})_{\max }$ denotes the maximum value attainable by $\Delta \mathrm{r}$ as $\underline{r}^{\prime}$ and $\underline{r}$ range independently over their respective domains, it can be shown that series in eq (15) will converge uniformly with respect to $\underline{r}$ and $\underline{r}^{\prime}$ for all $\underline{r}$ in $V$ and $\underline{r}^{\prime}$ in $V^{\prime}$. Hence if $|Q|^{2}$ and $\left|Q^{\prime a}\right|^{2}$ are integrable in their respective finite domains - as is physically reasonable - - the termby-term integration can be justified. One may incidentally verify that the contribution of $f_{1}$ to the series is indeed the result shown in eq $(5-4)$.

The discussion in this appendix thus far pertains directly only to the transmission integral, the simplest but most important term in the Liouville-Neumann series for $\mathrm{M}_{21}$. The procedure used may be extended to obtain expansions of the iterated integrals. The principal task is to secure a suitable representation for the scattering functions. ( $\underline{\text { f }}$ the purely electromagnetic case [22, §5].) Convergence criteria are of the same form as eq (17). 
The main features involved in obtaining eq (5-2) are the following. We obtain the Liouville-Neumann series for $M_{21}$ and $M_{22}$ by expanding the inverse operator in the respective eqs (3-12) and (3-13). We observe that the terms of $M_{21}$ each involve an odd number of transits of energy, the terms of $\mathrm{M}_{22}$ involve an even number, and find that the expansion of an integral involving $m$ transits of energy is of the form

$$
\frac{e^{i m k d}}{d^{m}}\left(C_{m 0}+C_{m 1} d^{-1}+C_{m 2} d^{-2}+\ldots\right) \text {. }
$$

Putting this information into eq (5-1), assuming $\mathrm{M}_{22} \Gamma_{\mathrm{L}}$ "small" (ordinarily $\left|M_{22} \Gamma_{L}\right|$ will be much less than unity), expanding, and rearranging ruthlessly, one finds that all resulting terms represent odd numbers of transits of energy, as written in eq $(5-2)$. 


\section{REFERENCES}

[1] D. M. Kerns, "Correction of near-field antenna measurements made with an arbitrary but known measuring antenna," Electronics Letters, 6 , pp. 346-347 (1970).

[2] D. M. Kerns, "New method of gain measurement using two identical antennas," Electronics Letters, $\underline{6}$, pp. 348-349 (1970).

[3] R. C. Baird, A. C. Newel1, P. F. Wacker, and D. M. Kerns, "Recent experimental results in nearfield antenna measurements," Electronics Letters, $\underline{6}$, pp. 349-351 (1970).

[4] A. C. Newell and D. M. Kerns, "Determination of both. polarisation and power gain of antennas by a generalised 3-antenna measurement method," Electronics Letters, $\underline{7}$, pp. 68-70 (1971).

[5] A.C. Newell, R.C. Baird, and P.F. Wacker, "Accurate measurement of antenna gain and polarization at reduced distances by an extrapolation technique," IEEE Trans. on Antennas and Propagation, AP-21, No. 4, pp. 418-431 (July, 1973).

[6] P.F. Wacker, "Theory and numerical techniques for accurate extrapolation of near-zone antenna and scattering measurements," unpublished NBS Report (April 1972).

[7] E.B. Joy and D.T. Paris, "Spatial sampling and filtering in near-field measurements," IEEE Trans. on Antennas and Propagation, AP-20, No. 3, pp. 253-261 (1972).

[8] W.J. Trott, "Underwater-sound transducer calibration from near-field data," Journal of the Acoustical Society of America, 36, pp. 1557-1568 (1964).

[9] G. Pida, "Large nearfield calibration array" (L), Journal of the Acoustical Society of America, 49, pp. 1683-1686, (1971).

[10] C.W. Horton and G.S. Innis, "Computation of far-field radiation pattern from measurements made near the source," Journal of the Acoustical Society of America, 33, pp. 877-880 (1961). 
[11] D.D. Baker, "Determination of far-field characteristics of large underwater sound transducers from near-field measurements," Journal of the Acoustical Society of America, 34, pp. 1737-1744 (1962).

[12] D.M. Kerns and E.S. Dayhoff, "Theory of diffraction in mic rowave interferometry," J. Res. NBS., 64B, No. 1, pp. $1-13$ (J an. 1960).

[13] A.D. Yaghjian, "Theory of adjoint reciprocity for electroacoustic transducers," NBSIR 73-329 (Feb. 1974).

[14] L.L. Foldy and H. Primakoff, "A general theory of passive linear electroacoustic transducers and the electroacoustic reciprocity theorem. I," Journal of the Acoustical Society of America, 17, pp. 109-120 $(1945)$.

[15] H. Primakoff and L.L. Foldy, "A general theory of passive linear electroacoustic transducers and the electroacoustic reciprocity theorem. II," Journal of the Acoustical Society of America, 19, pp. 50-58 (1947).

[16] D.M. Kerns and R.W. Beatty, Basic Theory of Waveguide Junctions and Introductory Microwave Network Analys is, p. 46 (Pergamon, 1967).

[17] D.M. Kerns, contribution in "High frequency and microwave field strength precision measurement seminar," unpublished NBS Report (March 1966).

[18] D.P. Petersen and D. Middleton, "Sampling and reconstruction of wave-number-1imited functions in $\mathrm{N}$-dimensional Euclidean spaces," Information and Control, 5 , pp. 279-323 (1962).

[19] N.M. Brenner, "Three FORTRAN programs that perform the Cooley-Tukey Fourier transform," Tech. Note 1967-2, Lincoln Lab., M.I.T., Lexington, Mass. (July 1967).

[20] H. Lamb, Hydrodynamics, p. 501 (Dover, 1945).

[21] L.M. Brekhovskikh, Waves in Layered Media (Trans. from Russian by David Lieberman), $\overline{\text { p. } 239}, \overline{\text { eqn. }} 17$ (Academic Press, 1960). 
[22] D.M. Kerns, "Plane-wave spectra and spectral coup1ing products for arbitrary radiating and scattering systems," unpublished NBS Report (March 1972).

[23] E. M. McMillan, "Violation of the reciprocity theorem in linear passive electromechanical systems," Journal of the Acoustical Society of America, 18, pp. 344-347 (1946).

[24] D.M. Kerns, "Scattering-matrix description and nearfield measurements of electroacoustic transducers," unpublished NBS Report (July 1972). 


\begin{tabular}{|c|c|c|c|}
\hline $\begin{array}{l}\text { U.S. DEPT. OF COMM. } \\
\text { BIBLIOGRAPHIC DATA } \\
\text { SHEET }\end{array}$ & $\begin{array}{l}\text { 1. PUBLICATION OR REPORT NO. } \\
\text { NBS TN-651 }\end{array}$ & $\begin{array}{l}\text { 2. Gov't Accession } \\
\text { No. }\end{array}$ & 3. Recipient's Accession No. \\
\hline \multirow{2}{*}{\multicolumn{3}{|c|}{$\begin{array}{l}\text { Scattering-Matrix Description and Near-Field Measurements } \\
\text { of Electroacoustic Transducers }\end{array}$}} & $\begin{array}{l}\text { 5. Publication Date } \\
\text { March } 1974\end{array}$ \\
\hline & & & 6. Performing Organization Code \\
\hline \multicolumn{3}{|c|}{ vid M. Kerns } & 8. Performing Organ. Report No. \\
\hline \multicolumn{3}{|c|}{$\begin{array}{l}\text { 9. PERFORMING ORGANIZATION NAME AND ADDRESS } \\
\text { NATIONAL BUREAU OF STANDARDS, Boulder Labs } \\
\text { DEPARTMENT OF COMMERCE } \\
\text { Boulder, CO } 80302\end{array}$} & $\begin{array}{l}\text { 10. Project/Task/Work Unit No. } \\
2725111 \\
\text { 11. Contract/Grant No. }\end{array}$ \\
\hline \multirow{2}{*}{\multicolumn{3}{|c|}{ 12. Sponsoring Organization Name and Complete Address (Street, City, State, ZIP) }} & $\begin{array}{l}\text { 13. Type of Report \& Period } \\
\text { Covered }\end{array}$ \\
\hline & & & 14. Sponsoring Agency Code \\
\hline
\end{tabular}

15. SUPPLEMENTARY NOTES

16. ABSTRACT (A 200-word or less factual summary of most significant information. If document includes a significant bibliography or literature survey, mention it here.)

Recently developed and successfully applied analytical techniques for the measurement of microwave antennas at reduced distances are "translated" into correspond ing techniques for the measurement of electroacoustic transducers in fluids. The basic theory is formulated in scattering-matrix form and emphasizes the use of plane-wave spectra for the representation of sound fields. This theory, in contrast to those base on asymptotic description of transducer characteristics, is suitable for the formulatio and solution of problems involving interactions at arbitrary distances. Two new techniques (in particular) are described: One, utilizing deconvolution of planar scann ing data, taken with a known transducer at distances d which may be much less than the Rayleigh distance $d_{R}\left(\equiv D^{2} / 2 \lambda\right)$, provides a means of obtaining complete effective directivity functions, corrected for the effects of the measuring transducer. Applicability of a (two-dimensional, spatial) sampling theorem and the "fast Fourier transform" algorithm, which greatly facilitate the necessary computations, is shown. Th second technique provides a means of extrapolating received signal as a function of distance (observed with $d \sim d_{R}$ ) to obtain on-axis values of effective directivity. 0the possible applications are indicated. These techniques rigorously utilize observed outp of non-ideal (but linear) measuring transducers.

17. KEY WORDS (six to twelve entries; alphabetical order; capitalize only the first letter of the first key word unless a proper name; separated by semicolons)

Electroacoustic transducer measurement techniques; near-field measurement techniques; scattering matrix description of electroacoustic transducers.

18. AVAILABILITY

For Official Distribution. Do Not Release to NTIS

Order From Sup. of Doc., U.S. Government Prigting Qffice

Washington, D.C. 20402, SD Cat. No.C13.46:651

Order From National Technical Information Service (NTIS) Springfield, Virginia $2215 \mathrm{I}$

\begin{tabular}{|l|c|}
\hline $\begin{array}{l}\text { 19. SECURITY CLASS } \\
\text { (THIS REPURT) }\end{array}$ & 21. NO. OF PAGE \\
UNCLASSIFIED & 40 \\
\hline $\begin{array}{l}\text { 20. SECURITY CLASS } \\
\text { (THIS PAGE) }\end{array}$ & 22. Price \\
UNCLASSIFIED & $\$ 50$ \\
\hline
\end{tabular}




\section{NATIONAL BUREAU OF STANDARDS}

The National Bureau of Standards " was established by an act of Congress March 3, 1901. The Bureau's overall goal is to strengthen and advance the Nation's science and technology and facilitate their effective application for public benefit. To this end, the Bureau conducts research and provides: (1) a basis for the Nation's physical measurement system, (2) scientific and technological services for industry and government, (3) a technical basis for equity in trade, and (4) technical services to promote public safety. The Bureau consists of the Institute for Basic Standards, the Institute for Materials Research, the Institute for Applied Technology, the Institute for Computer Sciences and Technology, and the Office for Information Programs.

THE INSTITUTE FOR BASIC STANDARDS provides the central basis within the United States of a complete and consistent system of physical measurement; coordinates that system with measurement systems of other nations; and furnishes essential services leading to accurate and uniform physical measurements throughout the Nation's scientific community, industry, and commerce. The Institute consists of a Center for Radiation Research, an Office of Measurement Services and the following divisions:

Applied Mathematics - Electricity - Mechanics - Heat - Optical Physics — Nuclear Sciences ${ }^{2}$ - Applied Radiation ${ }^{2}$ - Quantum Electronics ${ }^{3}$ - Electromagnetics ${ }^{3}$ - Time and Frequency" - Laboratory Astrophysics " C Cryogenics ".

THE INSTITUTE FOR MATERIALS RESEARCH conducts materials research leading to improved methods of measurement, standards, and data on the properties of well-characterized materials needed by industry, commerce, educational institutions, and Government; provides advisory and research services to other Government agencies; and develops, produces, and distributes standard reference materials. The Institute consists of the Office of Standard Reference Materials and the following divisions:

Analytical Chemistry - Polymers - Metallurgy - Inorganic Materials — Reactor Radiation - Physical Chemistry.

THE INSTITUTE FOR APPLIED TECHNOLOGY provides technical services to promote the use of available technology and to facilitate technological innovation in industry and Government; cooperates with public and private organizations leading to the development of technological standards (including mandatory safety standards), codes and methods of test; and provides technical advice and services to Government agencies upon request. The Institute consists of a Center for Building Technology and the following divisions and offices:

Engineering and Product Standards - Weights and Measures - Invention and Innovation - Product Evaluation Technology - Electronic Technology - Technical Analysis - Measurement Engineering - Structures, Materials, and Life Safety - Building Environment ${ }^{4}$ - Technical Evaluation and Application ${ }^{*}$ - Fire Technology.

THE INSTITUTE FOR COMPUTER SCIENCES AND TECHNOLOGY conducts research and provides technical services designed to aid Government agencies in improving cost effectiveness in the conduct of their programs through the selection, acquisition, and effective utilization of automatic data processing equipment; and serves as the principal focus within the executive branch for the development of Federal standards for automatic data processing equipment, techniques, and computer languages. The Institute consists of the following divisions:

Computer Services - Systems and Software - Computer Systems Engineering - Information Technology.

THE OFFICE FOR INFORMATION PROGRAMS promotes optimum dissemination and accessibility of scientific information generated within NBS and other agencies of the Federal Government; promotes the development of the National Standard Reference Data System and a system of information analysis centers dealing with the broader aspects of the National Measurement System; provides appropriate services to ensure that the NBS staff has optimum accessibility to the scientific information of the world. The Office consists of the following organizational units:

Office of Standard Reference Data - Office of Information Activities - Office of Technical Publications - Library — Office of International Relations.

\footnotetext{
1 Headquarters and Laboratories at Gaithersburg, Maryland, unless otherwise noted; mailing address Washington, D.C. 20234.

2 Part of the Center for Radiation Research.

Located at Boulder, Colorado 80302.

- Part of the Center for Building Technology.
} 
POSTAGE AND FEES PAID U.S. OEPARTMENT OF COMMERCE

OFFICIAL BUSINESS

Penalty for Private Use, $\$ 300$

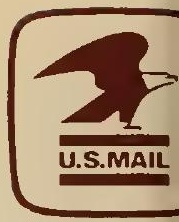

